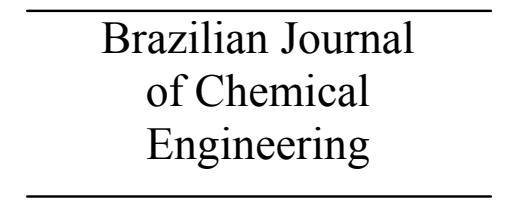

ISSN 0104-6632

Printed in Brazil

www.abeq.org.br/bjche

Vol. 29, No. 02, pp. 349 - 358, April - June, 2012

\title{
MIXING IN SHEAR THINNING FLUIDS
}

\author{
H. Ameur ${ }^{*}$ and M. Bouzit \\ Faculté de Génie Mécanique, USTO-MB, Oran, Algérie USTO-MB, Bt 1505 El M’nouar, Oran, Algérie. \\ E-mail: houari_am@yahoo.fr \\ E-mail: bouzit_mohamed@yahoo.fr
}

(Submitted: February 5, 2011 ; Revised: November 15, 2011 ; Accepted: November 20, 2011)

\begin{abstract}
In the present study, a CFD characterization of the flow generated by curved-blade impellers in a cylindrical unbaffled vessel was carried out. The tank diameter was $300 \mathrm{~mm}$, with a flat bottom. The liquid height was equal to the vessel diameter. The fluids simulated have a shear thinning behavior. Analyses concern the effect of the impeller speed, the fluid rheology and the number of impeller blades on the induced flow patterns and the power consumption. The predictions were compared with literature data and a satisfactory agreement was found.

Keywords: Stirred tanks; Curved-blade impeller; Shear thinning fluid; Number of impeller blades.
\end{abstract}

\section{INTRODUCTION}

Mixing plays a significant role in the process industries. This operation, one of the oldest in chemical engineering, consists of homogenizing a medium in a vessel using one or a combination of rotating impellers (Bonvillani et al., 2006). For a long time, the design of mixing systems was determined experimentally. This approach was timeconsuming and expensive and process scale-up was based on empirical rules established on pilot rigs. Nowadays, computer simulation of mixing flow (CFD) in the vessel is widely used to optimize the mixer geometries and to get a better insight into the complex flow patterns produced by the interaction between the impeller, the tank internals, and the vessel wall. Some reviews about CFD simulations of stirred vessels can be found in Sommerfeld and Decker (2004) and Muniz et al. (2007).

There is a wide range of mixing geometries available for viscous fluids and the selection of an appropriate design for a given application is not an easy task. Several criteria may be used, depending on the process requirements, such as specific power consumption, mixing time, pumping efficiency, shear rate distribution and flow field characteristics.
The absence of dead zones is of foremost importance for good homogenization.

Additional difficulties for the optimization of processes often occur with non-Newtonian fluids. In fact, the hydrodynamics strongly depend on the nature of the fluids involved in the mixing system (Peixoto et al., 2000; Dular et al., 2006). Shear thinning fluids are an important class of non-Newtonian fluids. Agitation of these fluids results in the formation of a zone of intense motion around the impeller (the so-called cavern) with essentially stagnant regions elsewhere. The term cavern was first used by Wichterle and Wein (1975) to describe the mobile zone around the impeller in extremely shear thinning suspensions of finely divided particulate solids. The poorly mixed stagnant regions give rise to poor mass and heat transfer (Amanullah et al., 1997). Thus, it is desirable to eliminate these stagnant regions by properly designing and operating agitation systems.

Several works have been conducted using various impellers to evaluate cavern size as a function of the power drawn by non-Newtonian fluids, including those by Galindo and Nienow $(1992,1993)$ for Lightnin A315 and Scaba 6SRGT impellers; Amanullah et al. (1997) for an axial flow Scaba 3SHPI impeller; Serrano-Carreon and Galindo

*To whom correspondence should be addressed 
(1997) for four different impellers (Rushton turbine, Chemineer He-3, CD-6 and Scaba 6SRGT) in individual and dual arrangements, and Pakzad et al. $(2007,2008)$ for Scaba 6SRGT impellers.

Others studies have been achieved with Newtonian fluids: Junker et al. (2000) for Rushton, Maxflo T, CD-6 and HE-3 impellers; Boon et al. (2002) for 6SRGT, A315 and 3SHP1 impellers with dual arrangement; Hokes et al. (2003) for Rushton turbine, Scaba 3SHP1 and 6SRGT impellers.

The objective of the present work is to investigate several design parameters affecting the fluid flow performance of a curved-blade turbine using computer simulations. Our attention is focused on the effects of the number of impeller blades, Reynolds number and fluid rheology. The study is restricted to the laminar and transition regimes with shear thinning fluids, which are typical conditions of polymerization reactions.

\section{STATEMENT OF THE PROBLEM}

The system consists of a cylindrical unbaffled tank with a flat bottom (Figure 1). The liquid level $\mathrm{h}$ is equal to the vessel diameter $\mathrm{D}$, with $\mathrm{D}=300 \mathrm{~mm}$. The impeller consists of curved blades fixed on a disc with $30 \mathrm{~mm}$ of diameter $\left(\mathrm{d}_{\mathrm{d}}\right)$ and $6 \mathrm{~mm}$ of thickness $\left(d_{t}\right)$, which is attached on a cylindrical central shaft of diameter $d_{s} / D=0.04$. Four impellers with different blade numbers $(\alpha)$ were used in this study: $\alpha=2,4,6$ and 8 , respectively. All of these impellers are placed at the same height position from the bottom of the tank: $\mathrm{c} / \mathrm{D}=0.5$.

\section{NUMERICAL DETAILS}

To perform the calculations, the commercially available computer code (CFX 11.0) developed by AEA Technology, UK, was used. In the following part, only the main points about the mixing system modeling options and numerical procedures will be given. For a detailed description, see Abid (1989).

CFX is a general purpose computer program using a finite volume method. The Navier-Stokes equations written in a rotating, cylindrical frame of references are solved. Because of the choice of a rotating frame, two terms are added to the equations: centrifugal and Coriolis accelerations. The equations are written in terms of velocity components and pressure. These variables are discretized on a grid of control volumes, which enables a more precise mass conservation and a faster convergence to be obtained. A pressure-correction method of the type Semi-Implicit Method for Pressure-Linked Equations-Consistent (SIMPLEC) is used to effect pressure-velocity coupling.

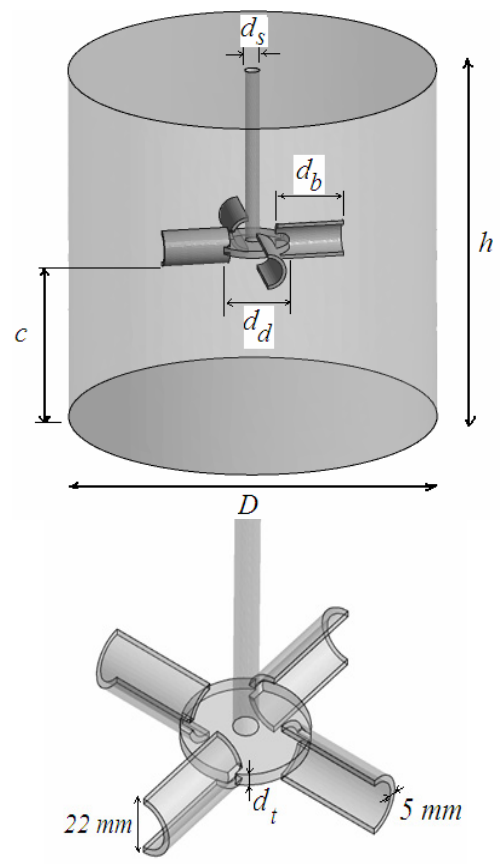

Figure 1: Mixing system 
Constant boundary conditions have been set, respecting a rotating reference frame (RRF) approach. Here, the impeller is kept stationary and the flow is steady relative to the rotating frame, while the outer wall of the vessel is given an angular velocity equal and opposite to the velocity of the rotating frame. This approach can be employed due to the absence of baffles. The same RRF approach, often used for stirred vessels, has given accurate results for several different stirring systems (Aubin et al., 2000; Naude, 1998). The simplification of the stirring system where baffles have been removed is obviously independent of the CFD resolution and is only due to mixing and industrial considerations. In the case of agitated vessels involving baffles, computational flow could nonetheless have been easily achieved with an MRF (Naude, 1998) or sliding meshes approaches.

In the case of an unbaffled vessel, the RRF approach should have no effect when changing the fluid (Newtonian or non-Newtonian) (Letellier et al., 2002). However, we have tested the case of a Newtonian fluid and compared the convergence performance and the mass imbalances between the different regions with those obtained for a nonNewtonian fluid.

A pre-processor (ICEM CFD 11.0) was used to discretize the flow domain with a tetrahedral mesh (Figure 2). An increased mesh density was used near the impeller and the tank walls in order to capture the boundary layer flow details. A sufficient number of nodes that define the curvature of the blades was created on the impeller edge to have a very refined mesh. Mesh tests were performed by verifying that additional cells did not change the velocity magnitude in the regions of high velocity gradients around the impeller blades by more than $2.5 \%$.

To verify the grid independency, the number of cells was increased by a factor of about 2 used by other researchers in CFD modeling of mixing processes (Buwa et al., 2006; Letellier et al., 2002). The original 3D mesh of the model had 90,123 computational cells. To verify the grid independency, the number of cells was increased from 90,123 cells to 180,246 cells. The additional cells changed the velocity magnitude in the regions of high velocity gradients and the impeller power number by more than $3 \%$. Thus, the number of cells was changed from 180,246 cells to 360,492 cells. The additional cells did not change the velocity magnitude in the regions of high velocity gradients and impeller power number by more than $2.5 \%$. Therefore, 180,246 cells were employed in this study.
It is important to correctly represent the boundary layer near the wall, since all moment is generated by the wall rotation. In our case, we have generated prismatic elements near these walls (Figure 2).

Simulations were considered to have converged when the scaled residuals for each transport equation were below $10^{-7}$. Most simulations required about 4000 iterations for convergence. Computations were carried out using a $2.20 \mathrm{GHz}$ Pentium(R) Dual Core CPU with 2.0 GB of RAM and convergence was typically achieved after 5-7 h.

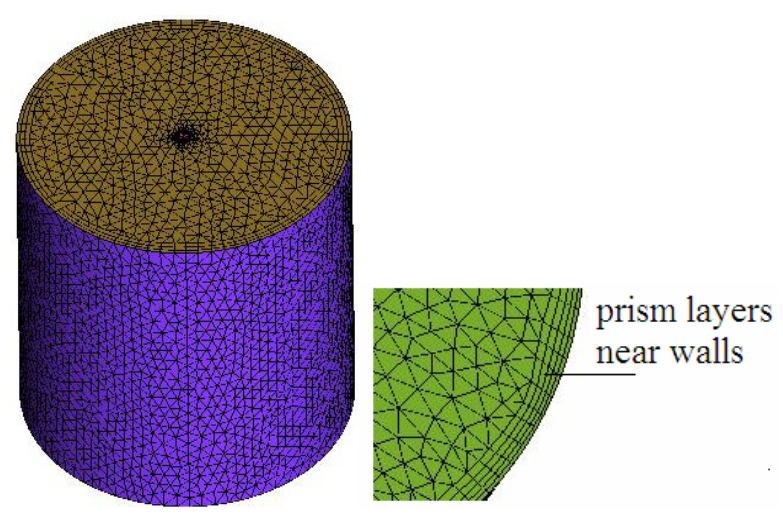

Figure 2: Numerical grid (tetrahedral mesh)

\section{MATHEMATICAL MODELING}

Simulations were carried out for liquids showing shear thinning behavior; the structural index (n) varied in the range of 0.4 to 1 . For a Newtonian fluid, the Reynolds number is given by:

$$
R e=\frac{\rho \mathrm{ND}^{2}}{\eta}
$$

where $\mathrm{N}$ is the rotational speed of the impeller, and $\rho$ the density. For a shear thinning fluid (Ostwald model):

$$
R e_{\mathrm{g}}=\frac{\rho \mathrm{N}^{2-\mathrm{n}} \mathrm{D}^{2}}{\mathrm{~m}}
$$

where $\mathrm{m}$ is the consistency index and $\mathrm{n}$ the power law index.

The power consumption is a macroscopic result obtained by integration on the impeller surface of the local power transmitted by the impeller to the fluid. It is quite equivalent to say that the power consumption $\mathrm{P}$ is entirely transferred by the impeller to the fluid. In these conditions: 


$$
\mathrm{P}=\eta \int_{\text {vessel volume }} Q_{v} \mathrm{dv}
$$

where $\mathrm{Q}_{\mathrm{v}}$ is the viscous dissipation.

The element $d v$ is written as:

$\mathrm{dv}=\mathrm{rdr} d \theta \mathrm{dz}$

$\mathrm{Q}_{\mathrm{v}}=\left(2 \tau_{\mathrm{rr}}^{2}+2 \tau_{\theta \theta}^{2}+2 \tau_{\mathrm{zz}}^{2}+\tau_{\mathrm{rz}}^{2}+\tau_{\mathrm{r} \theta}^{2}+\tau_{\mathrm{z} \theta}^{2}\right) / \eta^{2}$

$\tau_{\mathrm{rr}}=-\eta 2 \partial \mathrm{v}_{\mathrm{r}} / \partial \mathrm{r}$

$\tau_{\mathrm{r} \theta}=-\eta\left[\mathrm{r} \partial\left(\mathrm{v}_{\theta} / \mathrm{r}\right) / \partial \mathrm{r}+(1 / \mathrm{r}) \partial \mathrm{v}_{\mathrm{r}} / \partial \theta\right]$

$\tau_{\mathrm{rz}}=-\eta\left[\partial \mathrm{v}_{\mathrm{r}} / \partial \mathrm{z}+\partial \mathrm{v}_{\mathrm{z}} / \partial \mathrm{r}\right]$

The power number is calculated as:

$\mathrm{N}_{\mathrm{P}}=\frac{\mathrm{P}}{\rho \mathrm{N}^{3} \mathrm{D}^{5}}$

\section{VERIFICATION AND VALIDATION}

Initially, before the presentation of the predicted results, it is necessary to validate the CFD computer code; for this task, the review of Pakzad et al. (2007) provided appropriate data and geometrical parameters. With the same working fluid used by Pakzad, the predicted results for radial and axial velocity components were calculated (Figures 3 and 4). The comparison between our results and those given experimentaly by Pakzad shows good agreement.

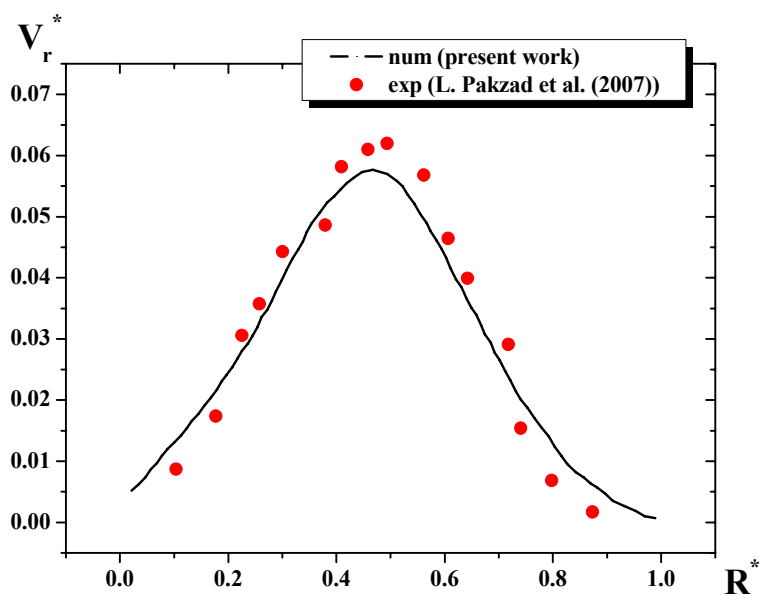

Figure 3: Radial velocity for $\mathrm{Re}_{\mathrm{y}}=21.5, \mathrm{n}=0.12$, $Z^{*}=0.21, \theta=-45^{0}$

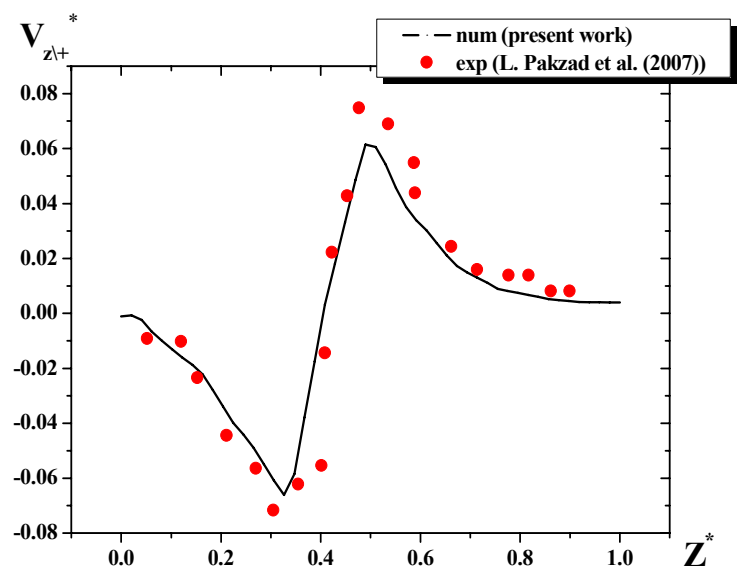

Figure 4: Axial velocity for $\mathrm{Re}_{\mathrm{y}}=80.9, \mathrm{n}=0.12$, $\mathrm{R}^{*}=0.36, \theta=-45^{0}$

\section{RESULTS AND DISCUSSION}

\section{Effect of the Reynolds Number}

We begin the analysis by testing the effect of the hydrodynamic regime on the flow field generated.

The study is limited to just the laminar and transition regimes. Four different values of the generalized Reynolds number were chosen $\left(\mathrm{Re}_{\mathrm{g}}=10\right.$, 40,80 and 300 , respectively) to exhibit the flow structure induced at the same cross-sectional plane (Figure 5). At a low Reynolds number, $\mathrm{Re}_{\mathrm{g}}=10$, the circulation of fluid particles is of low intensity, but the increase of $\operatorname{Re}_{\mathrm{g}}\left(\mathrm{Re}_{\mathrm{g}}=40\right)$ yields a stream directed horizontally from the blade to the vertical walls of the tank; the flow is then divided into streams: one downward to the tank bottom and redirected vertically to the impeller, the other upward to the free surface of the liquid and going along the impeller shaft, forming two recirculation loops. The further increase of $\operatorname{Re}_{\mathrm{g}}\left(\mathrm{Re}_{\mathrm{g}}=80\right)$ produces a more powerful radial flow, which gives a vortex of appreciable size. For the highest Reynolds number $\left(\mathrm{Re}_{\mathrm{g}}=300\right)$, these rolls detach from the blade tip, going far in the direction of the vertical walls of the tank, the velocity reaching more volume of the vessel.

For more details on the vortex size generated by this type of turbine, we have presented in Figure 6 the axial velocity component. The minus sign of $\mathrm{V}_{\mathrm{z}}{ }^{*}$ indicates the presence of recirculation flow. For the first case, $\operatorname{Re}_{\mathrm{g}}=0.1$, no recirculation is noted, but for the three other cases, the vortices are present and increase continuously with $\mathrm{Re}_{\mathrm{g}}$. 

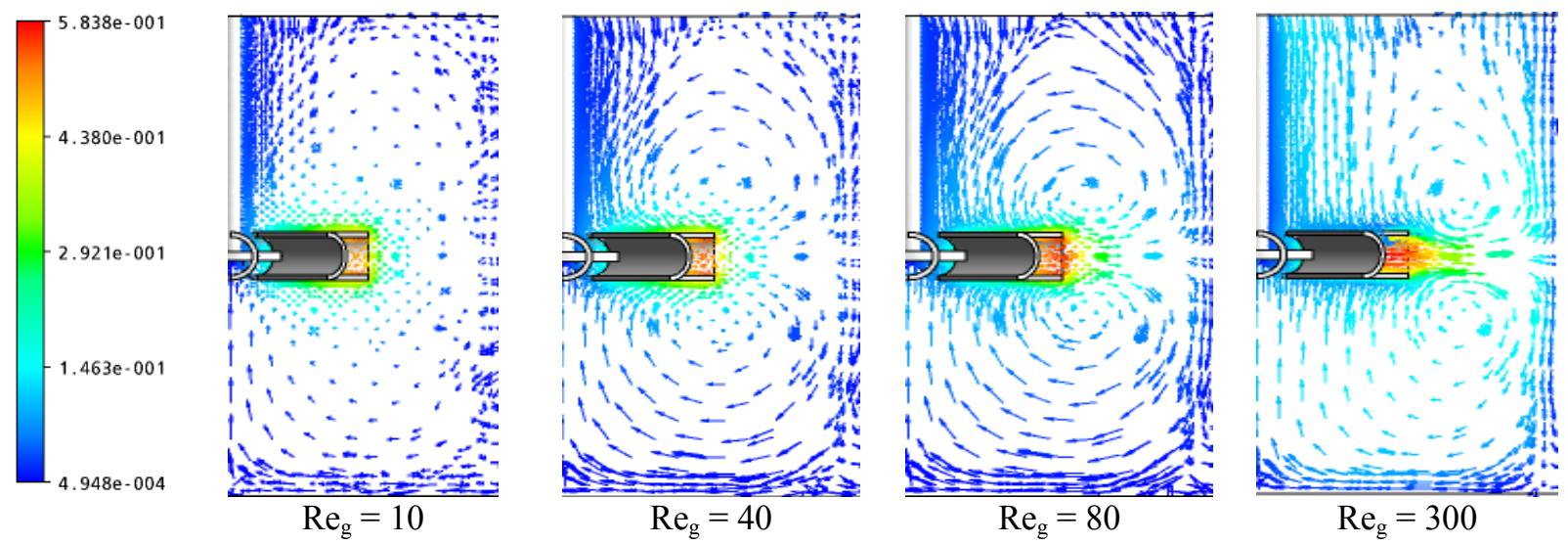

Figure 5: Velocity vectors for $\mathrm{n}=0.7, \alpha=8$

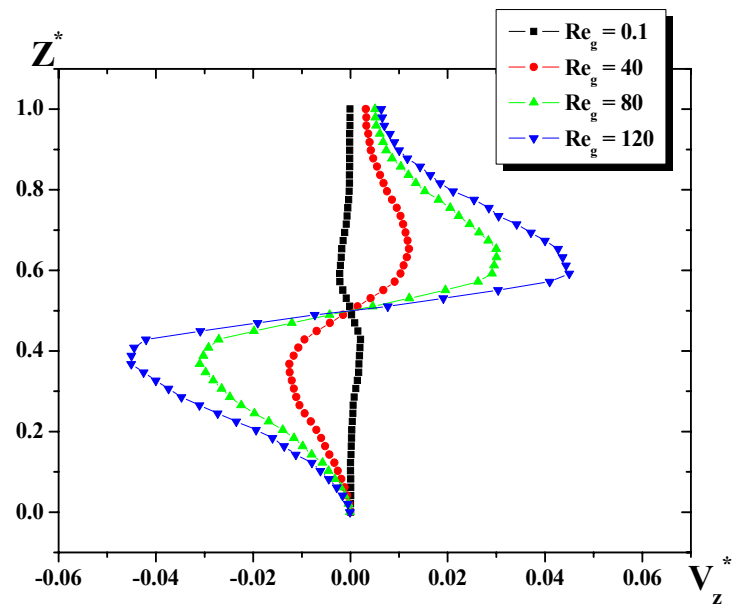

Figure 6: Axial velocity for $\mathrm{n}=0.7, \mathrm{R}^{*}=0.4, \theta=0^{0}, \alpha=8$

As was mentioned earlier, the agitation of pseudoplastic fluids results in the formation of a well mixed region (cavern) around the impeller and essentially stagnant and/or slow moving fluid elsewhere in the vessel. Velocity magnitude contours, shown in Figure 7, were used to estimate the effect of the Reynolds number on the cavern dimensions (diameter and height). At Reynolds numbers less than 20, the cavern has a torus shape. This region of the Reynolds number is not particularly important from a design point of view (Pakzad et al., 2007). At $\mathrm{Re}_{\mathrm{g}}>20$, the caverns were oval in shape and became more important in size. These results agreed well compared to those of Pakzad et al. (2007).

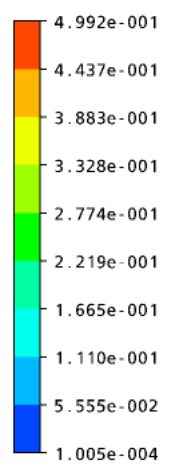

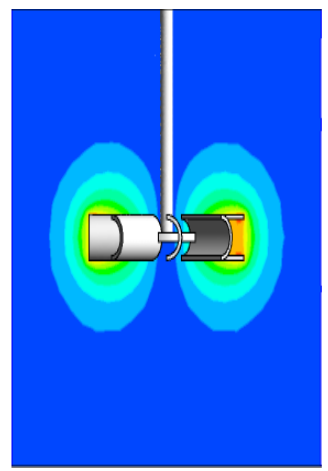

$\operatorname{Re}_{\mathrm{g}}=1$

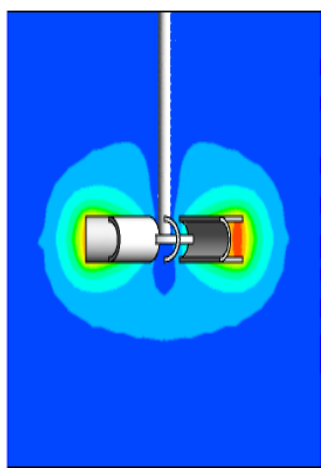

$\mathrm{Re}_{\mathrm{g}}=50$

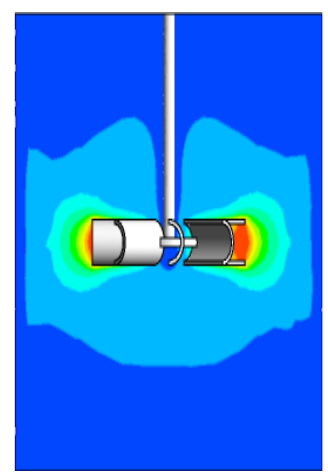

$\operatorname{Re}_{\mathrm{g}}=100$

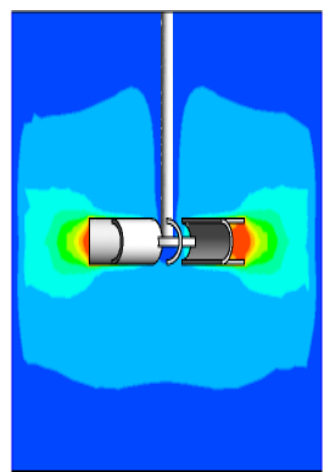

$\operatorname{Re}_{\mathrm{g}}=150$

Figure 7: Velocity contours induced at $\mathrm{n}=0.7, \alpha=8$ 


\section{Effect of the Rheological Behavior}

The rheological parameters of the fluid also have an important effect on the flow fields generated. For this task, four values of the structural index (n) were chosen $(0.4,0.6,0.8$ and 1). In Figure 8, the tangential velocity profiles as a function of the vessel radius, at the mid-height of the impeller blade, show a maximum at the blade tip for any value of the structural index. When this parameter (n) is lower, the momentum transfer is less intense, because of the viscous forces, which explains the speed decay curves (for $\mathrm{n}=0.8,0.6$ and 0.4 , respectively). The change in the radial velocity component along the height of the vessel as a function of the rheological behavior is presented in Figure 9, with results analogous to those of Figure 8.

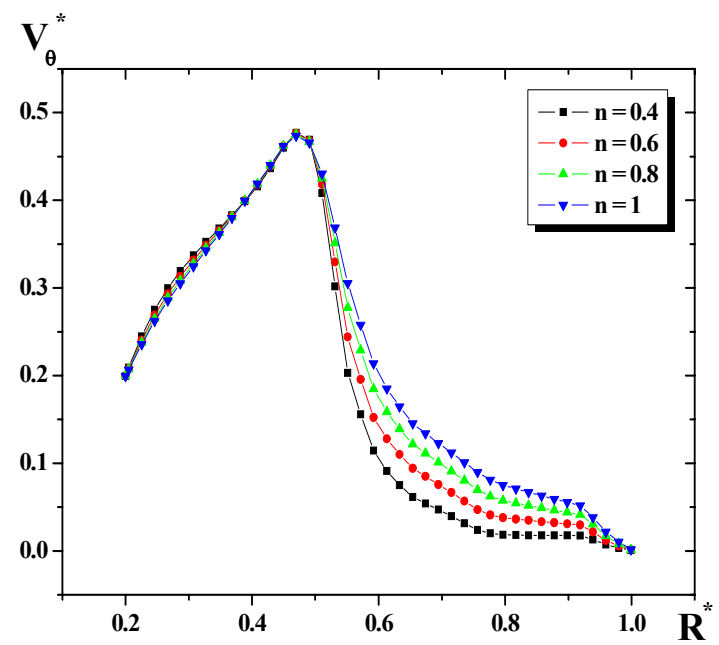

Figure 8: Tangential velocity for $\operatorname{Re}_{\mathrm{g}}=70, \mathrm{Z}^{*}=0.5$, $\theta=0^{0}, \alpha=4$

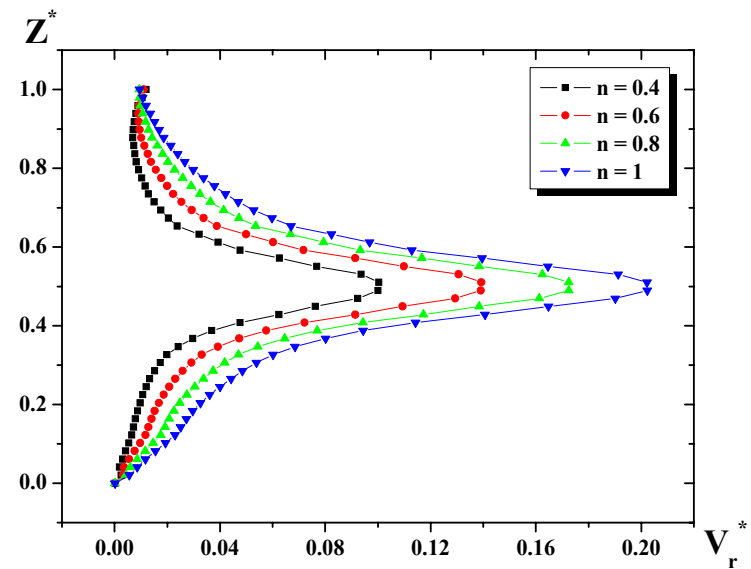

Figure 9: Radial velocity for $\operatorname{Re}_{\mathrm{g}}=70, \mathrm{R}^{*}=0.3$, $\theta=0^{0}, \alpha=4$.
The flow fields induced for different structural indices are shown in a vertical cross-sectional plane (Figure 10). Clearly, the increase in flow index produces an important shear rate: for $\mathrm{n}=0.4$, the recirculation loops are located in the area swept by the blade; the vortex become larger in size, with a center located far from the blade, when the power law index increases.

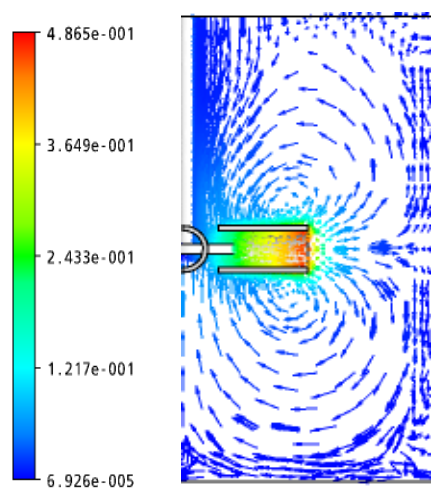

$\mathrm{n}=0.4$

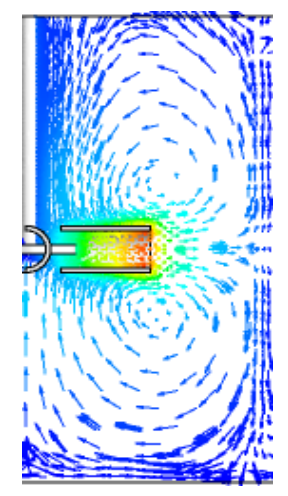

$\mathrm{n}=1$
Figure 10: Velocity vectors for $\operatorname{Re}_{\mathrm{g}}=70, \alpha=4$

To illustrate the effect of the rheological behavior on the vortex size, the axial velocity was followed as a function of the vessel height (Figure 11).

Figure 12 illustrates the velocity contours obtained for a Reynolds number $\operatorname{Re}_{\mathrm{g}}=70$ and four bladed impeller $(\alpha=4)$ at various flow indices If the flow index is low, the zone of intense motion is limited to the area swept by the turbine, but the increase of this parameter (n) enlarges the cavern (well mixed region) size.

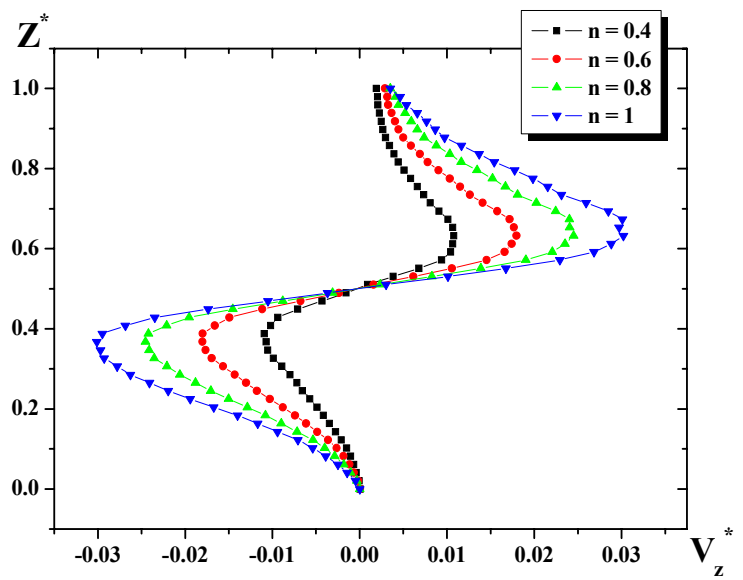

Figure 11: Axial velocity for $\operatorname{Re}_{\mathrm{g}}=70, \mathrm{R}^{*}=0.4$, $\theta=0^{0}, \alpha=4$ 


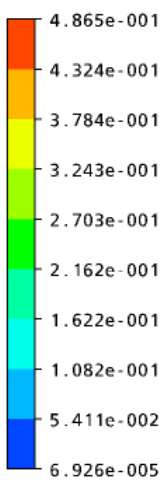

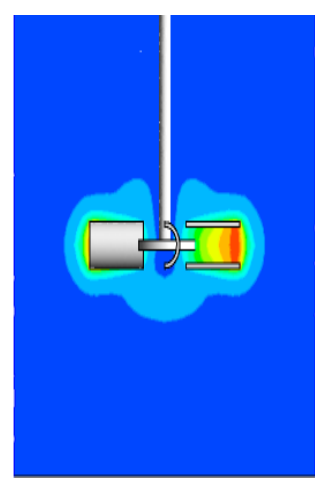

$\mathrm{n}=0.4$

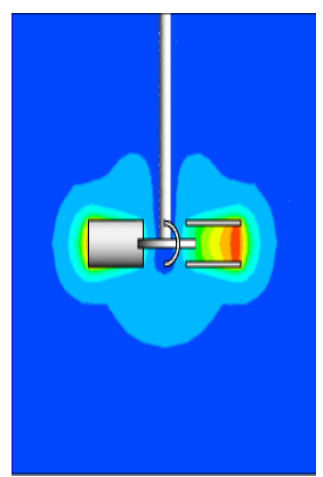

$\mathrm{n}=0.6$

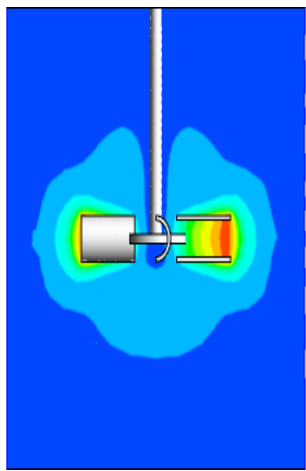

$\mathrm{n}=0.8$

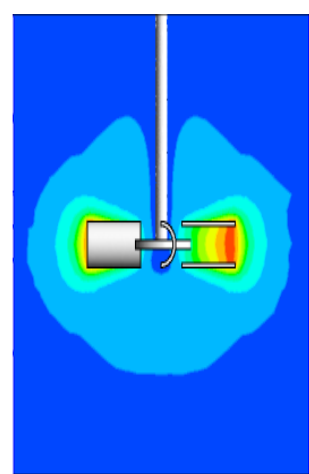

$\mathrm{n}=1$

Figure 12: Velocity contours induced at $\operatorname{Re}_{\mathrm{g}}=70, \alpha=4$

The mixing power constitutes a global parameter to describe the performance of a mechanically stirred system. The dimensional analysis enables us to characterize power consumption through the power number Np. Figure 13 represents the variations of $\mathrm{Np}$ versus $\mathrm{Re}_{\mathrm{g}}$ on a logarithmic scale, it can be seen that, at Reynolds numbers less than 10, the power number changes linearly with the slope of -1 . In the transition regime, this variable changes slightly with $\mathrm{Re}_{\mathrm{g}}$. On the other hand, for a more pronounced flow index, the power provided is greater.

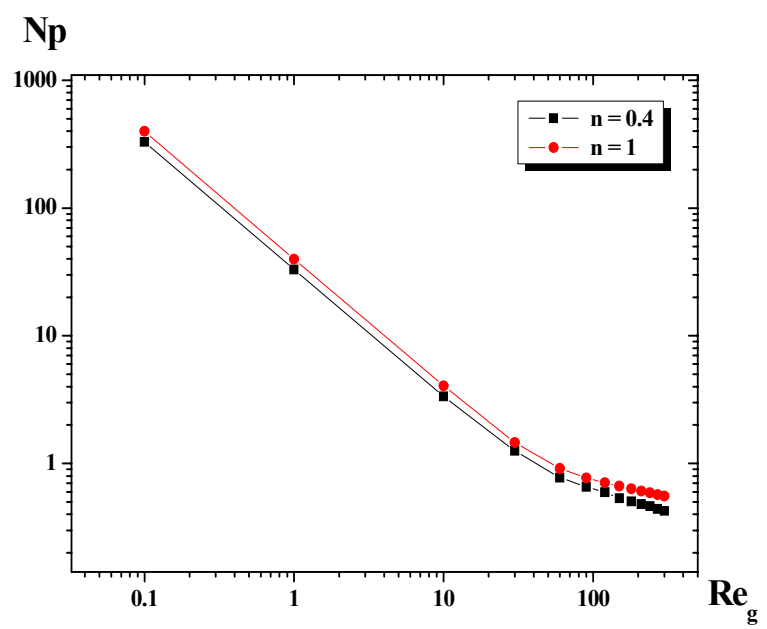

Figure 13: Power number for $\alpha=4$

\section{Effect of the Number of Impeller Blades}

The impeller design plays an important role in the mixing process; for this type of curved blade mixer, we investigated the effect of the blade number on its performance. Four cases $\alpha=2, \alpha=4, \alpha=6$ and $\alpha=8$, were analyzed.

The profiles of the tangential velocity component are plotted for different numbers of impeller blades (Figure 14). These results reveal that the maximum is reached at the blade tip for any case, but the curve decay is faster with impellers that contain a lower number of blades. On the other hand, the difference between an impeller with six and eight blades is small when compared with the other cases. The same can be noted for the radial velocity component (Figure 15).

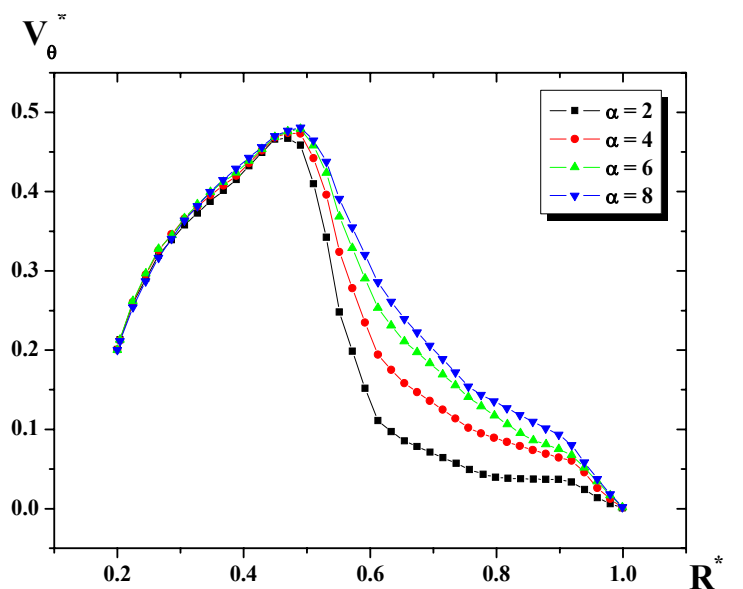

Figure 14: Tangential velocity for $\mathrm{n}=0.9, \mathrm{Re}_{\mathrm{g}}=100$, $\mathrm{Z}^{*}=0.5$

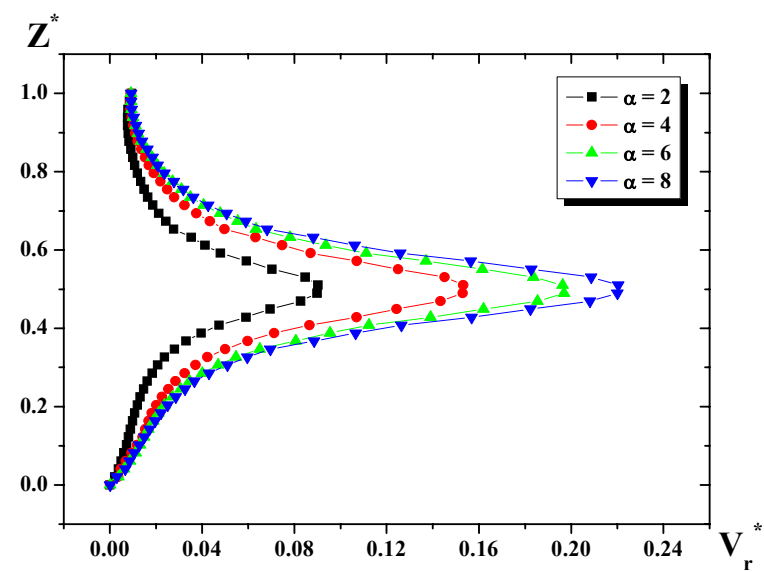

Figure 15: Radial velocity for $\operatorname{Re}_{\mathrm{g}}=50, \mathrm{n}=0.8$ 
The ongoing demand for improved impeller designs usually comes from the users of industrial mixing equipment when the vessels are being designed for new plants or when an improvement in the existing design is desired for enhancing quality, capacity, process efficiency and energy efficiency.

For meeting these objectives, it is imperative that the relationship between the flow pattern and the design objective is understood. One of the flow characteristics affecting the impeller flow efficiency is the presence of trailing vortices generated at the tip of the impeller blades.

Predicted vectors of the flow generated by curved blade impellers at $\mathrm{Re}_{\mathrm{g}}=300$ and $\mathrm{n}=0.4$ in the vertical plane aligned with the impeller shaft are presented in Figure 16. For the four cases, the plots show two circulating loops, one below and one above the impeller. However, the increase in blades number enhances the axial pumping and increases the mixing ability.

The profiles of axial velocity are depicted in dimensionless form relative to the impeller tip velocity $\pi \mathrm{ND}$ to show more clearly the vortex size (Figure 17). As shown, the size of the recirculation loops increases continuously with $\alpha$, but between the third and fourth cases $(\alpha=6$ and 8$)$ the difference is small.

The path lines of the flow produced by the four impellers are depicted in Figure 18, in a horizontal section plane located at the mid-height of the tank. These plots show a zone of intense motion near the impeller and stagnant and/or slow moving fluid elsewhere within the mixing vessel. The maximum is found at the blade tip for any case. The size of the well mixed region (cavern) is greater with the increase of $\alpha$.

Power consumption is usually used in the design of equipment. Therefore, a detailed knowledge of the power of stirred tank configurations is required. Figure 19 represents the variations of the power number $\mathrm{Np}$ as a function of the number of impeller blades. The power number of the impeller with $\alpha=2$ is 2.28 at the Reynolds number $\operatorname{Re}_{\mathrm{g}}=10$ and structural index $n=0.4$. The power numbers of other impellers at the same Reynolds number are $3.34(\alpha=4)$, $3.92(\alpha=6)$ and $4.23(\alpha=8)$, respectively. The value of the power number increases as the number of impeller blades increases when compared at the same Reynolds number and flow behavior index. The second point to be noted is the small difference in power number between $\alpha=6$ and 8 when compared with the other cases.

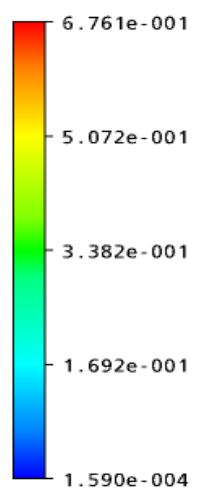

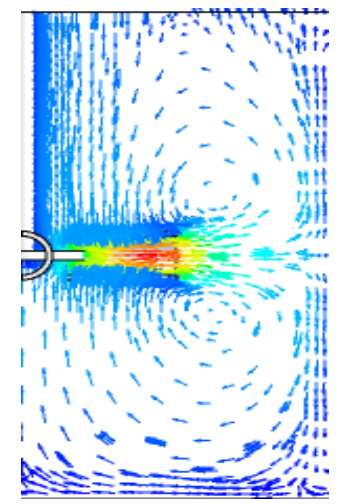

$\alpha=4$

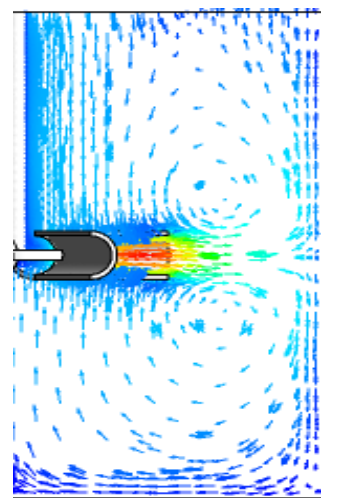

$\alpha=6$

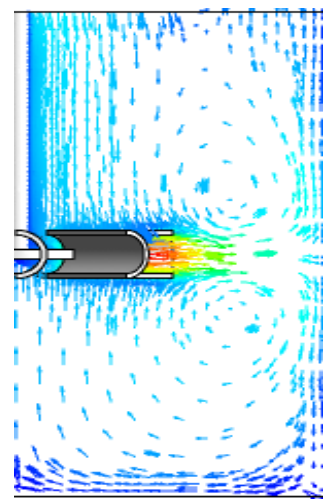

$\alpha=8$

Figure 16: Velocity vectors for $\mathrm{n}=0.4, \mathrm{Re}_{\mathrm{g}}=300$

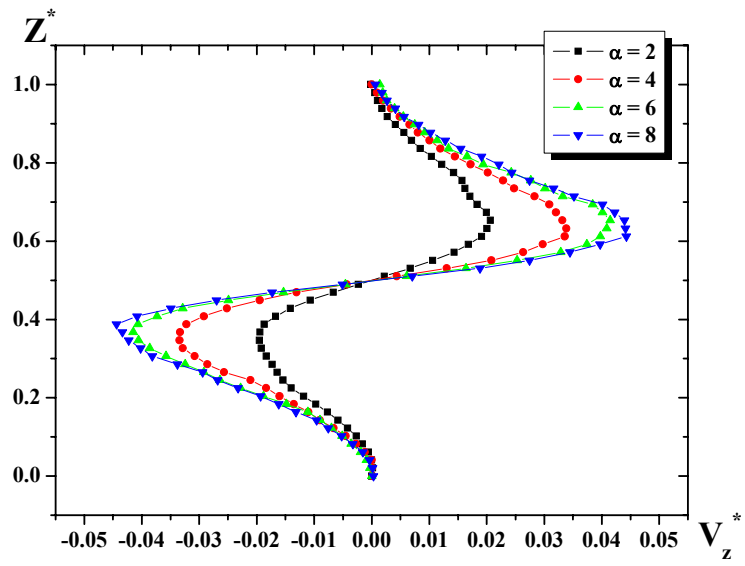

Figure 17: Axial velocity for $\mathrm{n}=0.9, \mathrm{Re}_{\mathrm{g}}=100, \mathrm{R}^{*}=0.45$ 


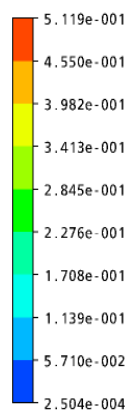

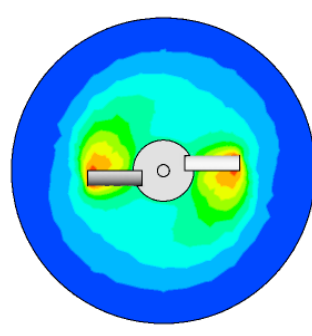

$\alpha=2$

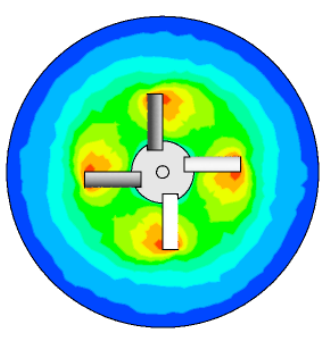

$\alpha=4$

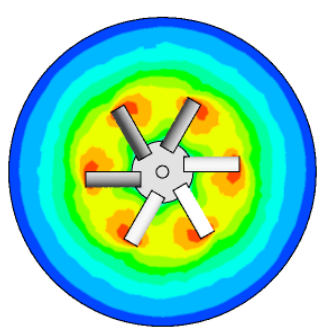

$\alpha=6$

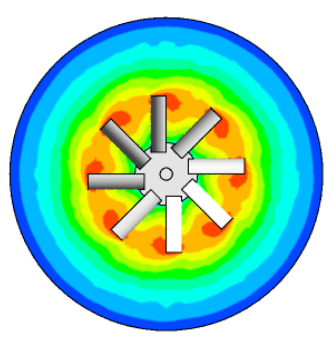

$\alpha=8$

Figure 18: Velocity contours induced at $\operatorname{Re}_{\mathrm{g}}=100, \mathrm{n}=0.9, \mathrm{Z}^{*}=0.5$

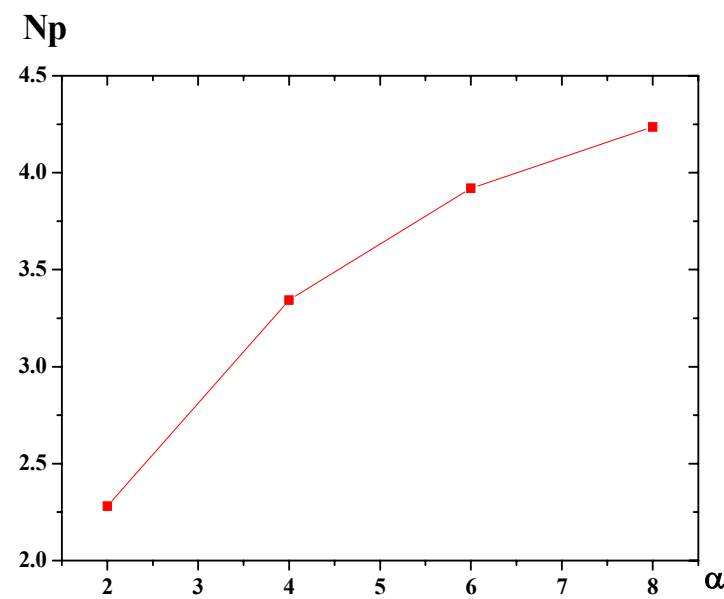

Figure 19: Power number for $\operatorname{Re}_{\mathrm{g}}=10, \mathrm{n}=0.4$

\section{CONCLUSION}

In this work, a numerical characterization of the hydrodynamics of curved-blade impellers has been carried out in the laminar and transition regime with shear thinning fluids. The effect of the Reynolds number, the fluid rheology and the number of impeller blades on performance has been investigated. The cavern size and the power consumption are higher for extreme shear thinning fluids. The Reynolds number and the number of impeller blades also strongly influence the cavern size and the mixing power. The best performance is achieved for a low power law index, high Reynolds number and low blade number.

\section{NOMENCLATURE}

c impeller clearance from the tank bottom

$\mathrm{d}_{\mathrm{d}} \quad$ disc diameter

$\mathrm{d}_{\mathrm{b}} \quad$ blade diameter

$\mathrm{d}_{\mathrm{s}} \quad$ shaft diameter

$\mathrm{m}$

$\mathrm{m}$

$\mathrm{m}$ $\mathrm{d}_{\mathrm{t}} \quad$ disc thickness

$\mathrm{m}$

$\mathrm{h} \quad$ liquid height

$\mathrm{m} \quad$ consistency index

$\mathrm{n} \quad$ power law index

D tank diameter

$\mathrm{N} \quad$ impeller rotational speed

$\mathrm{P} \quad$ power

$\mathrm{Np} \quad$ power number

$\mathrm{Q}_{\mathrm{v}} \quad$ viscous dissipation function

$\mathrm{R}$ radial coordinate

Re Reynolds number for a

Newtonian fluid

$\mathrm{Re}_{\mathrm{g}} \quad$ Reynolds number for a shear thinning fluid

$\mathrm{V} \quad$ velocity

$\mathrm{m} / \mathrm{s}$

$\mathrm{V}_{\mathrm{z}} \quad$ axial velocity

$\mathrm{V}_{\theta} \quad$ tangential velocity

$\mathrm{V}_{\mathrm{r}} \quad$ radial velocity

$\mathrm{Z} \quad$ axial coordinate

$\mathrm{m} / \mathrm{s}$

$\mathrm{m} / \mathrm{s}$

$\mathrm{m} / \mathrm{s}$

$\mathrm{m}$

\section{Greek Letters}

$\gamma$

shear rate 
shear stress

fluid density

angular coordinate

number of impeller blades

\section{REFFERENCES}

Abid, M., Agitation mécanique de fluids visqueux: contribution à l'étude des écoulements tridimensionnels. Thèse d'état INP Toulouse, France (1989).

Amanullah, A., Hjorth, S. A., Nienow, A. W., Cavern sizes generated in highly shear thinning viscous fluids by Scaba 3SHP1 impeller. Food Bioprod. Process, 75, 232-238 (1997).

Aubin, J., Naude, I., Xuereb, C., Bertrand, J., Blending of Newtonian and shear-thinning fluids in a tank stirred with a helical screw agitator. Trans. Inst. Chem. Eng., 78, (A), 1105-1114 (2000).

Armenante, P. M., Luo, C., Chou, C. C., Fort, I., Medek, J., Velocity profiles in a closed, unbaffled vessel: comparison between experimental LDV data and numerical CFD prediction. Chem. Eng. Sci., 52, 3483-3492 (1997).

Bonvillani, P., Ferrari, M. P., Ducros, E. M., Orejas, J. A., Theoretical and experimental study of the effects of scale-up on mixing time for a stirredtank bioreactor. Braz. J. Chem. Eng., 23, 1-7 (2006).

Boon, L. A., Hoeks, F. W. J. M. M., van der Lans, R. G. J. M., Bujalski, W., Wolff, M. O., Nienowd, A. W., Comparing a range of impellers for stirring as foam disruption (SAFD). Biochemical Eng. J., 10, 183-195 (2002).

Buwa, V., Dewan, A., Nasser, A. F., Durst, F., Fluid dynamics and mixing of single-phase flow in a stirred vessel with a grid disc impeller: experimental and numerical investigations. Chem. Eng. Sci., 61, 2815-2822 (2006).

Dular, M. Bajcar, T., Slemenik-Perše, L., Zumer, M., Širok, B., Numerial simulation and experimental study of non-newtonian mixing flow with a free surface. Braz. J. Chem. Eng., 23, 4, 473-486 (2006).

Galindo, E., Nienow, A. W., Mixing of highly viscous simulated xanthan fermentation broths with the Lightnin A-315 impeller. Biotechnol. Prog., 8, 233-239 (1992).

Galindo, E. and Nienow, A. W., The performance of the Scaba 6SRGT agitator in the mixing of simulated xanthan gum broths. Chem. Eng. Technol., 16, 102-108 (1993).

Hoeks, F., Boon, L., Studer, F., Wolff, M., van der Schot, F., Vrabe, P., van der Lans, R., Bujalski, W., Blomsten, G., Hjorth, S., Scale-up of stirring as foam disruption (SAFD) to industrial scale. J. Ind. Microbiol. Biotechnol., 30, 118-128 (2003).

Junker, B. H., Mann, Z., Hunt, G., Retrofit of CD-6 (Smith) impeller in fermentation vessels. Applied Biochemistry and Biotechnology, 89, 67-83 (2000).

Letellier, B., Xuereb, C., Swaels, P., Hobbes, P., Bertrand, J., Scale-up in laminar and transient regimes of a multi-stage stirrer, a CFD approach. Chem. Eng. Sci., 57, 4617-4632 (2002).

Muniz, A. R., Secchi, A. R., Cardozo, N. S. M. High-order finite volume method for solving viscoelastic fluid lows. Braz. J. Chem. Eng., 25, 1, 153-166 (2008).

Naude, I., Simulations Directes de Mobiles en Cuve Agitée. Contribution à l'Optimisation du Choix d'un Agitateur, Ph.D. thesis, INPT, France (1998).

Pakzad, L., Ein-Mozaffari, F., Chan, P., Using computational fluid dynamics modeling to study the mixing of pseudoplastic fluids with a Scaba 6SRGT impeller. Chem. Eng. and Proc., 47, 2218-2227 (2007).

Pakzad, L., Ein-Mozaffari, F., Chan, P., Using electrical resistance tomography and computational fluid dynamics modeling to study the formation of cavern in the mixing of pseudoplastic fluids possessing yield stress. Chem. Eng. Sc., 63, 25082522 (2008).

Peixoto, S. M. C., Nunhez, J. R., Duarte, C. G., Characterizing the flow of stirred vessels with anchor type impellers. Braz. J. Chem. Eng., 17, 925-936 (2000).

Serrano-Carreon, L., Galindo, E., Studies on cavern development in mixing a yield stress fluid in a pilot-scale Proto-Fermenter. Récents Progrès en Génie des Procédés 11, 161-168 (1997).

Sommerfield, M., Decker S., State of the art and future trends in CFD simulation of stirred vessel hydrodynamics. Chem. Eng. Technol., 27, 215224 (2004).

Wichterle, K., Wein, O., Agitation of concentrated suspensions. Presented in CHISA, Paper B4.6, Prague, Czechoslovakia (1975). 